\title{
MONITORING OXIDATIVE STRESS ACROSS WORSENING CHILD PUGH CLASS OF CIRRHOSIS
}

\author{
SUMIT BHANDARI, MUKUL P. AGARWAL, S. DWIVEDI, B. D. BANERJEE1
}

\section{ABSTRACT}

CONTEXT: Oxidative stress has been increasingly implicated in the pathogenesis and progression of cirrhosis. AIMS: We studied oxidative stress in patients with cirrhosis by measuring markers reflecting pro-oxidant (serum malondialdehyde-MDA) and antioxidant factors (RBC catalase-CAT, superoxide dismutase-SOD and blood reduced glutathione-GSH) factors. The level of oxidative stress was also assessed with respect to functional compromise of liver, as determined by Child Turcotte Pugh (CTP) scoring. DESIGN: Case-controlled retrospective study. MATERIALS AND METHODS: Twenty-three patients of cirrhosis along with 23 age and sex matched healthy controls were studied. Exclusion criteria were concurrent use of anti-oxidant drugs; co-existing diseases like DM, CKD; alcohol use, gastrointestinal bleed or blood transfusion within previous 2 weeks. Besides routine investigations, MDA, CAT, SOD and GSH levels were measured and compared with controls. STATISTICAL ANALYSIS: Continuous variables were recorded as mean \pm SD; ANOVA-f test, followed by Tukey's test, was used to evaluate the significance of difference $(P<0.05)$ among groups. RESULTS: Mean age of patients was $41.04 \pm 12.3$ yrs. Patients showed a significant increase in MDA \{control $3.31 \pm$ 0.25 (95\% Cl 3.21-3.41), Child B $6.30 \pm 0.4$ (95\% Cl 6.03-6.53), Child C $8.05 \pm 0.66$ $(95 \% \mathrm{Cl} 7.29-8.81) \mathrm{nmol} / \mathrm{l}$ \} and a significant decrease in levels of SOD control 845.13 \pm 36.44 (95\% Cl 829.92-860.34), Child B 582.91 \pm 42.12 (95\% Cl 557.45-608.32), Child C $489.5 \pm 17.66(95 \% \mathrm{Cl} 479.3-499.7) \mathrm{U} / \mathrm{gm} \mathrm{Hb}$, CAT \{controls $2.54 \pm 0.22$ (95\% Cl 2.45-2.63), Child B $1.93 \pm 0.23(95 \%$ Cl 1.72-2.14), Child C $1.46 \pm 0.10(95 \%$ $\mathrm{Cl}$ 1.40-1.52) $\mathrm{U} / \mathrm{gm} \mathrm{Hb}$ \} and GSH \{controls $6.52 \pm 0.25$ (95\% Cl 6.42-6.52), Child B $3.85 \pm 0.18(95 \% \mathrm{Cl} 3.74-3.96)$, Child C $2.99 \pm 0.30(95 \% \mathrm{Cl} 2.82-3.16) \mathrm{mmol} / \mathrm{gm} \mathrm{Hb}$. CONCLUSIONS: Oxidative stress is associated with the development and progression of cirrhosis.

Key words: Humans, cirrhosis, oxidative stress, reactive oxygen species, lipid peroxidation

Departments of Medicine and ${ }^{1}$ Biochemistry, University College of Medical Sciences and GTB Hospital, New Delhi-110 095, India

Correspondence:

Dr. Sumit Bhandari

B-87/2, Naraina Vihar, New Delhi-110 028, India.

E-mail: sumitbhandari06@gmail.com

DOI: $10.4103 / 0019-5359.48456$

\section{INTRODUCTION}

Oxidative stress is defined as an imbalance between pro-oxidant and antioxidant

Presentation at a meeting: Oral Poster Presentation Organization Asia-Pacific Association for Study of Liver (APASL) $-14^{\text {th }}$ Biennial conference 
mechanisms in our body, the balance being tilted in favor of the former. ${ }^{[1]}$ It has been unequivocally implicated in the pathogenesis and pathophysiology of many fibroprofilerative diseases such as atherosclerosis, glomerulonephritis, pulmonary fibrosis and cirrhosis. ${ }^{[2]}$

Previous studies have demonstrated a correlation between hepatic and plasma glutathione. ${ }^{[3]}$ Glutathione is a tripeptide synthesized in the liver which acts as an antioxidant. Erythrocyte antioxidant enzymes, such as superoxide dismutase (SOD) and catalase (CAT) have been found to be deranged in alcoholic liver disease, predisposing them to a hemolytic pattern. ${ }^{[4]}$

Lipoperoxide concentrations, which signify increased free radical production, have been found to be elevated in liver and serum in patients with cirrhosis..$^{[5]}$

The present study was undertaken to assess the oxidative stress with respect to functional compromise of liver (as determined by ChildPugh scoring), by measuring pro-oxidant (serum MDA) and antioxidant (RBC SOD and CAT, reduced glutathione-GSH) factors in patients with cirrhosis, and comparing them with corresponding values in age and sex matched controls.

\section{MATERIALS AND METHODS}

After informed consent, 23 patients of cirrhosis (19 male, 4 female) aged between 24 to 65 years (median age 46 years), consecutively admitted in our department, entered the study. An equal number of age and sex matched healthy volunteers were recruited. Exclusion criteria were concurrent use of anti-oxidant drugs; co-existing diseases like diabetes mellitus (DM), chronic kidney disease (CKD); alcohol use within previous 2 weeks; gastrointestinal bleed or blood transfusion within previous 2 weeks.

Diagnosis of cirrhosis was based on the clinical profile with biochemical and radiological investigations and a liver biopsy unless contraindicated.

The predominant etiology of cirrhosis in 17 cases of cirrhosis was alcohol abuse, while chronic viral hepatitis was the cause in four cases, and two remained of cryptogenic origin. Eleven cases were cirrhosis belonging to Child's grade B and 12 had Child's grade C cirrhosis.

Besides routine investigation, biochemical tests to measure serum MDA, RBC CAT and SOD, and blood GSH were done.

Serum MDA level was measured as an index of lipid peroxidation using Satoh calorimetric method. ${ }^{[6]}$ This assay is based upon the reaction of TBA (thiobarbaturic acid) with MDA, one of the aldehyde products of lipid peroxidation. The absorbance of the MDA-TBA adduct produced was measured at $532 \mathrm{~nm}$ spectrophotometrically.

The erythrocyte SOD activity was determined by the method described by Marklund and Marklund, as modified by Nanda and Chatterjee. ${ }^{[7,8]}$ This method is based on the inhibition of pyrogallol auto-oxidation brought about by SOD. 
Erythrocyte catalase (CAT) activity was determined by the method of Sinha. ${ }^{[9]}$ This is based on the principle that dichromate in acetic acid is reduced to chromic acid when heated in the presence of $\mathrm{H}_{2} \mathrm{O}$, with the ultimate production of chromic acetate, which is measured at $570 \mathrm{~mm}$.

Reduced glutathione is measured by Teitze's method $^{[10]}$. This is based on the development of yellow color with DTNB (5,5, dithiobis-2nitrobenzoic acid), which is measured at $412 \mathrm{~mm}$.

\section{Statistical analysis}

The cases were assigned a Child Pugh class. The continuous variables were recorded as a

Table 1: Clinical and biochemical parameters of the study group

\begin{tabular}{lcc}
\hline Parameter & Cases $(n=23)$ & Controls $(n=23)$ \\
\hline Age $(\mathrm{years})$ & $41.04 \pm 12.3$ & $41.89 \pm 12.55$ \\
$\mathrm{Hb}(\mathrm{gm} / \mathrm{dl})$ & $10.8 \pm 1.85$ & $11.9 \pm 1.67$ \\
ESR $(\mathrm{mm} / \mathrm{hr})$ & $21.2 \pm 7.4$ & $16.8 \pm 8.9$ \\
Total Serum Bilirubin & & \\
$(\mathrm{mg} / \mathrm{dl})$ & $2.59 \pm 1.77$ & $0.80 \pm 0.15$ \\
Direct Bilirubin $(\mathrm{mg} / \mathrm{dl})$ & $1.67 \pm 1.20$ & $0.43 \pm 0.10$ \\
Total Protein $(\mathrm{gm} / \mathrm{dl})$ & $6.57 \pm 1.36$ & $5.72 \pm 0.34$ \\
Serum Albumin $(\mathrm{gm} / \mathrm{dl})$ & $2.86 \pm 0.70$ & $3.76 \pm 0.27$ \\
Serum Globulin $(\mathrm{gm} / \mathrm{dl})$ & $3.71 \pm 0.97$ & $1.93 \pm 0.11$ \\
A/G ratio & $0.82 \pm 0.27$ & $1.97 \pm 0.10$ \\
ALT (units/l) & $39.86 \pm 21.15$ & $33.91 \pm 11.41$ \\
Alkaline Phosphatase & & \\
(units/l) & $179.57 \pm 45.64$ & $132.10 \pm 30.26$ \\
Blood Urea (mg/dl) & $28.83 \pm 11.47$ & $22.34 \pm 10.38$ \\
S. Total Cholesterol (mg/dl) & $142.4 \pm 31.6$ & $178.2 \pm 28.4$ \\
S. Total Glycerides $(\mathrm{mg} / \mathrm{dl})$ & $104.2 \pm 21.4$ & $136.6 \pm 25.7$ \\
Ascites & $18 / 23$ & - \\
Hepatic Encephalopathy & $9 / 23$ & - \\
Esophageal Varices & $14 / 23$ & - \\
\hline
\end{tabular}

mean with standard deviation. The significance of difference between the various groups was calculated using the ANOVA-f test, followed by Tukey's test to ascertain whether the differences between the various groups were clinically significant $(P<0.05)$.

\section{RESULTS}

The clinical and biochemical parameters of the study subjects were as shown in Table 1.

All the cases had evidence of decompensation in the form of ascites and/or hepatic encephalopathy, reflecting the fact that cirrhosis goes largely undetected in initial stages in our country.

The pro-oxidant and anti-oxidant markers in the blood of cirrhotics are shown in Table 2, with corresponding levels in controls. A further comparison reflecting the differences in these values in worsening cases (as determined by Child-Pugh scoring) is also shown.
A significant increase in serum MDA value in cases was noted $(P<0.05)$. On further assigning the cases as per Child Pugh scoring, Child $\mathrm{C}$ cirrhosis had a worsening level of oxidative stress [Figure 1].

A significant decrease in antioxidant markers,

Table 2: Parameters of oxidative stress in cases and controls

\begin{tabular}{lcccccc}
\hline & Controls $(n=23)$ & Cases $(n=23)$ & $P$ value & Child $B(n=11)$ & Child C $(n=12)$ & $P$ value \\
\hline Serum MDA & $3.31 \pm 0.25$ & $7.22 \pm 1.06$ & $P=3.65 \times 10^{-21}$ & $6.30 \pm 0.49$ & $8.05 \pm 0.66$ & $P=7.75 \times 10^{-07}$ \\
nmol/ml (95\% Cl) & $(3.21-3.41)$ & $(6.78-7.66)$ & & $(6.03-6.53)$ & $(7.29-8.81)$ & \\
Erythrocyte SOD & $845.13 \pm 36.94$ & $534.17 \pm 56.91$ & $P=2.34 \times 10^{-25}$ & $582.19 \pm 42.12$ & $489.50 \pm 17.66$ & $P=7.71 \times 10^{-07}$ \\
U/gm Hb (95\% Cl) & $(829.92-860.34)$ & $(510.38-557.96)$ & & $(557.45-608.32)$ & $(479.3-499.7)$ & \\
Erythrocyte Catalase & $2.54 \pm 0.22$ & $1.68 \pm 0.29$ & $P=2.44 \times 10^{-14}$ & $1.93 \pm 0.23$ & $1.46 \pm 0.10$ & $P=2.19 \times 10^{-06}$ \\
U/gm Hb (95\% Cl) & $(2.45-2.63)$ & $(1.56-1.80)$ & & $(1.72-2.14)$ & $(1.40-1.52)$ & \\
Blood Glutathione & $6.52 \pm 0.25$ & $3.40 \pm 0.50$ & $P=1.05 \times 10^{-28}$ & $3.85 \pm 0.18$ & $2.99 \pm 0.30$ & $P=7.05 \times 10^{-11}$ \\
$\mu$ mol/gm Hb (95\% Cl) & $(6.42-6.62)$ & $(3.19-3.61)$ & & $(3.74-3.96)$ & $(2.82-3.16)$ & \\
\hline
\end{tabular}

MDA: Serum Malondialdehyde (nmol/ml), CAT: Erythrocyte Catalase (units/gm Hb), SOD: Erythrocyte Superoxide Dismutase (units/ gm Hb), GSH: Blood Glutathione ( $\mu \mathrm{mol} / \mathrm{gm} \mathrm{Hb})$ 
RBC CAT, SOD and blood GSH was noted. On grading the cases as per Child Pugh scoring, Child $C$ had a significantly reduced level of antioxidant markers [Figures 1-4].

\section{DISCUSSION}

Liver fibrosis was considered the result of repeated steatosis and chronic hepatitis until Lewis et al. hypothesized that the individual susceptibility of alcoholics to cirrhosis was due to variation in free radical scavenging enzymes and accumulated free radicals like superoxide. ${ }^{[11]}$

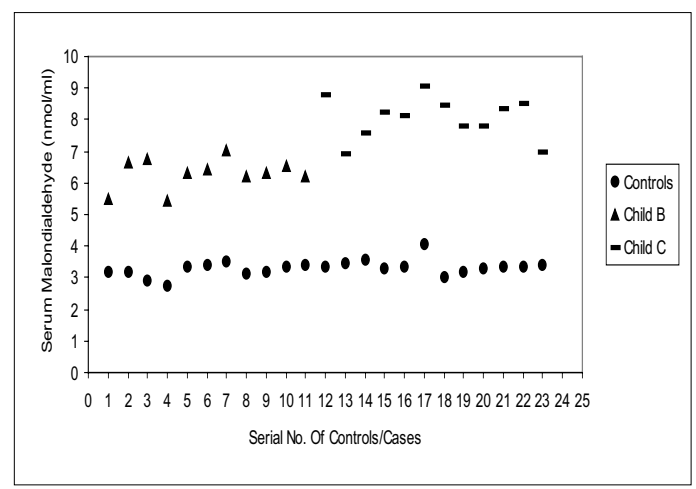

Figure 1: Serum Malondialdehyde in Controls and Cases (Child B and Child C)

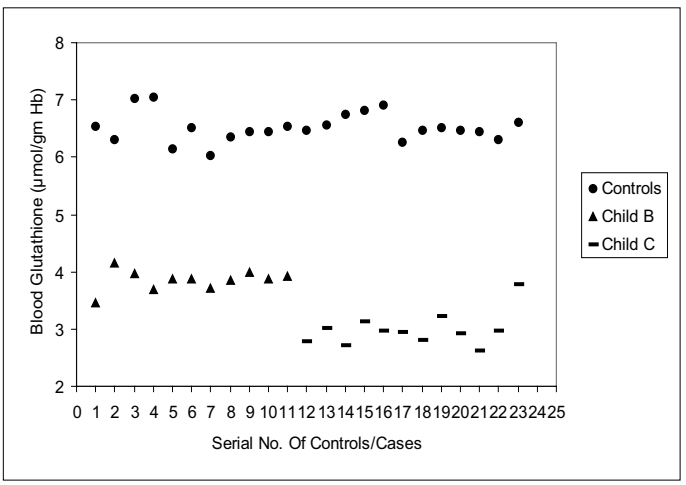

Figure 3: Erythrocyte SOD in Controls and Cases (Child $B$ and Child C)
The proposal that oxidative stress has a direct causative role in liver fibrogenesis was first put forth by Chojkier et al., who demonstrated (with cultured fibroblasts) the in vitro evidence of a possible molecular linkage between enhanced lipid peroxidation and induction of collagen gene expression. ${ }^{[12]}$ The proposal was subsequently extended to the in vivo model when Houglum et al. established a close association between liver fibrosis induced by iron overload and protein adduct epitopes of MDA and 4-hydroxynonenal (HNE), another lipoperoxide aldehyde product. ${ }^{[13]}$

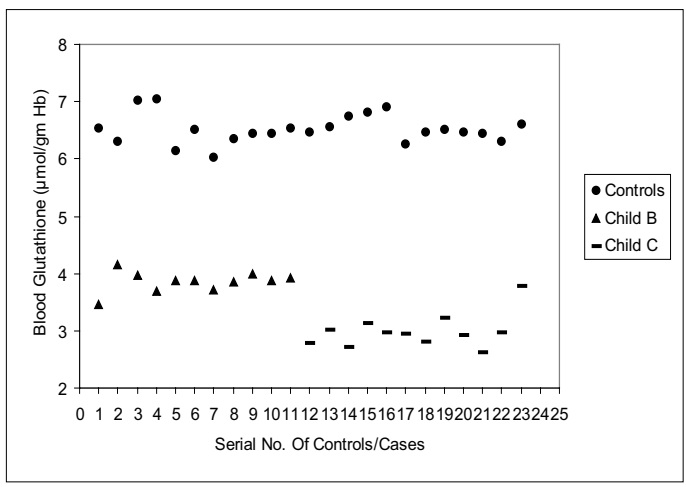

Figure 2: Blood Glutathione in Controls and Cases (Child $B$ and Child C)

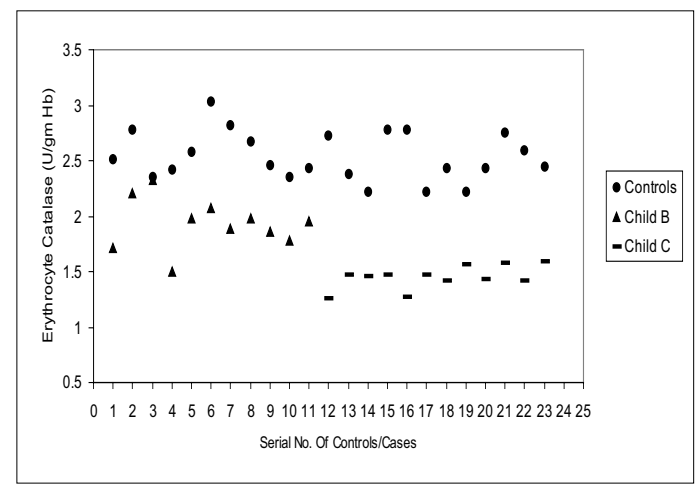

Figure 4: Erythrocyte Catalase in Controls and Cases (Child B and Child C) 
Bedossa et al. have demonstrated the co-localization of increased collagen $\alpha-1$ messenger RNA with carbon tetrachloride induced lipid peroxidation, by means of in situ hybridization and immunohistochemical studies in cultured rat hepatocytes. ${ }^{[5]}$ Muraca et al. demonstrated that antioxidant supplementation was able to depress procollagen $\alpha-1$ m-RNA over-expression. ${ }^{14]}$

A role of oxidative stress in the pathogenesis of chronic liver disease has been proposed by several authors using animal and human studies. ${ }^{[15-17]}$ The aim of our study was to assess the changes, if any, in the levels of markers reflecting oxidative stress across worsening Child scores.

Serum MDA was significantly elevated across worsening Child scores. Previous studies, in rat and micropig model of experimental liver cirrhosis induced by alcohol and iron, found increased level of MDA and HNE in the liver. ${ }^{[17,18]}$ Iron potentiated fibrogenesis was associated with intense and diffuse staining for MDA and HNE protein adducts. A significant increase in plasma TBARS has been noted in the plasma of 38 patients with cirrhosis by Yasa et al., with no significant difference between erythrocyte thiobarbituric acid reactive substances (TBARS) between controls and patients. ${ }^{[19]}$ Significant increase in the level of plasma MDA in cirrhotics was noted by Nalini et al. ${ }^{[20]}$ However, in a study by Clot et al., there were no significant differences between erythrocyte and plasma lipoperoxides in patients with cirrhosis and controls. ${ }^{[21]}$

There was a significant decrease in erythrocyte SOD in our cases across worsening Child Pugh class. A similar trend has been noted in previous studies. [19,20] However, Gerli et al., in a study involving 73 cirrhotics (22 Child A, 30 Child B, and 21 Child $C$ ) and 50 controls, demonstrated no significant difference between erythrocyte SOD among various groups. ${ }^{[4]}$ The disparities between these studies may be explained by different biochemical methods applied and the acute condition of the patients, given the fact that Child Pugh class may vary if there is any precipitating factor such as pharmacological incompliance (with a substantial intra class variability in patient profile).

Erythrocyte CAT was significantly lower in our cases, as compared to controls. A similar trend was noted by Gerli et al., with the decline in RBC CAT correlating well with the decline in liver function, as assessed by Child Pugh classification. ${ }^{[4]}$

The level of GSH was reduced across worsening Child class of cirrhosis. A significant decline in RBC GSH was noted by various authors. ${ }^{[4,20]}$ It should be noted that a decline in RBC GSH correlates well with decline in blood GSH. It is also pertinent to note that investigators have shown that decrease in the level of GSH in blood reflects parallel decrease in level of GSH in the liver. [22]

The biochemical pathways by which oxidative stress may cause cell injury are lipid peroxidation of membranes, oxidative modification of proteins and lesions in DNA. ${ }^{[1]}$ Studies in intragastric ethanol fed rats 
have shown that the accumulation of MDA in the liver is associated with the development of antibodies recognizing protein MDA adducts. ${ }^{[23]}$ Steward $S$ et al. have further characterized peripheral blood mononuclear cell (PBMC) and antibody responses to human serum albumin (HSA) adducts to MDA. ${ }^{[24]}$ They observed that alcoholic patients with cirrhosis had significantly higher cellular and humoral immune response to HSA-MDA adducts than controls and alcoholic patients without cirrhosis, implicating a role of cellular and humoral immunity in oxidative stress induced cirrhosis.

Hence, various mechanisms by which oxidative stress may play a role in the pathogenesis and progression of chronic liver disease are stimulation of hepatic stellate cells, Kupffer cells, immune system and apoptosis. ${ }^{[25,26]}$

The chief drawback in our study is a small sample size. A correlation between oxidative stress in blood and liver biopsy specimens was desirable, but for the fact that there were obvious contra-indications to perform a liver biopsy (such as a deranged coagulation profile, ascites) in many patients. Being a cross-sectional study, sequential samples were not taken. However, care was taken to rule out any precipitating factor like GI bleed, acute infection which could influence oxidative stress, and the cases were relatively stable within their calculated ChildPugh class.

\section{CONCLUSIONS}

Our study shows that Child class $\mathrm{C}$ cirrhosis has greater oxidative stress than Child class $B$ cirrhosis suggesting that greater liver damage is associated with more oxidative stress.

This needs to be corroborated in further studies with a larger sample size along with serial assessment of oxidative stress and its correlation with the (histopathological) progression of cirrhosis. This can also serve as a background for assessing the role of anti-oxidants in preventing the progression of cirrhosis.

\section{ACKNOWLEDGMENT}

We would like to acknowledge the highly cooperative and motivating role of the patients and volunteers without whom this study would not have been possible. We would also like to thank the Departments of Medicine and Biochemistry of University College of Medical Sciences and GTB Hospital, New Delhi where this study was conducted.

\section{REFERENCES}

1. Halliwell B, Gutteridge JMC, Cross CE. Free radicals, antioxidants, and human disease; Where are we now? J Lab Clin Med 1992;598620.

2. Poli G, Parola M. Oxidative damage and fibrogenesis. Free Rad Biol Med 1997;22:287305.

3. Shigesawa T, Sato C, Marumo F. Significance of plasma glutathione measurements in patients with alcoholic and non-alcoholic liver disease. J Gastroenterol Hepatol 1992;7:7-11.

4. Gerli G, Locatelli GF, Mongiat R, Zenoni L, Agostoni A, Moschini G, et al. Erythrocyte antioxidant activity, serum ceruloplasmin and 
trace element levels in subjects with alcoholic liver disease. Am J Clin Path 1992;97:614-8.

5. Bedossa P, Houglum K, Trautwein C, Holstege A, Chojkier M. Stimulation of collagen alpha (I) gene expression is associated with lipid peroxidation in hepatocellular injury; A link to tissue fibrosis? Hepatology 1994;19:1262-71.

6. Satoh K. Serum lipid peroxide in cerebrovascular disorders determined by a new colorimetric method. Clin Chem Acta 1978;90:37-43.

7. Marklund S, Marklund G. Involvement of the superoxide anion radical in the autooxidation of pyrogallol and a convenient assay for superoxide dismutase. Eur J Biochem 1974;47:469-74.

8. Nandi A, Chatterjee IB. Assay of superoxide dismutase activity in animal tissues. J Biosci 1988;13:305-15.

9. Sinha AK. Colorimetric assay of catalase. Anal Biochem 1972;47:389-94.

10. Tietze F. Enzymic method for quantitative determination of nanogram amounts of total and oxidized glutathione: Applications to mammalian blood and other tissues. Anal Biochem 1969;27:503-22.

11. Lewis KO, Paton A. Could superoxide cause cirrhosis? Lancet 1982;2:188-9.

12. Chojkier M, Houglum K, Solis-Herruzo J, Brenner DA. Stimulation of collagen gene expression by ascorbic acid in cultured human fibroblasts: A role for lipid peroxidation? J Biol Chem 1989;264:16957-62.

13. Houglum K, Fillip M, Witzum JL, Chojkier M. Malondialdehyde and 4 hydroxynonenal protein adducts in plasma and liver of rats with iron overload. J Clin Invest 1990;86:1991-8.

14. Parola M, Muraca R, Dianzani I, Barrera G, Leonarduzzi G, Bendinelli P, et al. Vitamin E dietary supplementation inhibits transforming growth factor $\beta 1$ gene expression in the rat liver. FEBS Lett 1992;308:267-70.

15. Pietrangelo A, Gualdi R, Casalgrandi G, Montosa G, Ventura E. Molecular and cellular aspects of iron induced hepatic cirrhosis in rodents. J Clin Invest 1995;95:1824-31.

16. Chen MF, Mo LR, Lin RC, Kuo JY, Chang $\mathrm{KK}$, Liao $\mathrm{C}$, et al. Increase of resting levels of superoxide anion in the whole blood of patients with decompensated liver cirrhosis. Free Radiat Biol Med 1997;23:672-9.

17. Niemela O, Parkkila S, Yla-Herttuala S, Villanueva J, Ruebner B, Halsted CH. Sequential acetaldehyde production, lipid peroxidation and fibrogenesis in a micropig model of alcohol induced liver disease. Hepatology 1995;22:1208-14.

18. Tsukamoto H, Horne W, Kamimura S, Niemela O, Parkkila S, Yla-Herttuala S, et al. Experimental liver cirrhosis induced by alcohol and iron. J Clin Invest 1995;96:620-30.

19. Hadi Yasa M, Kacmaz M, Serda Ozturk H, Durak I. Antioxidant status of erythrocytes from patients with cirrhosis. Hepatogastroenterology 1999;46:2460-3.

20. Nalini G, Hariprasad C, Narayanan VA. Oxidative stress in alcoholic liver disease. Indian J Med Res 1999;110:200-3.

21. Clot P, Tabone M, Arico S, Albano E. Monitoring oxidative damage in patients with liver cirrhosis and different daily alcohol intake. Gut 1994;35:1637-43.

22. Bell H, Bjorneboe A, Eidswoll B, Norum $\mathrm{KR}$, Raknerud N, Try K, et al. Reduced concentration of $\alpha$-tocpherol and glutathione in patients with alcoholic liver disease. Alcohol Alcohol 1992;27:39-46.

23. Albano E, Clot $P$, Morimoto M, Tomasi A, Ingelman-Sundberg $M$, French SW. Role of cytochrome P-450 2E1-dependent formation of hydroxyethyl free radical in the development of liver damage in rats intragastrically fed with alcohol. Hepatology 1996;23:155-63.

24. Stewart SF, Vidali M, Day CP, Albano E, Jones DE. Oxidative stress as a trigger for cellular immune responses in patients with alcoholic liver disease. Hepatology 2004;39:197-203.

25. Tsukamoto H, Rippe R, Niemela O, Lin M. Role 
of oxidative stress in activation of Kupffer and Ito cells in liver fibrogenesis. J Gastroenterol Hepatol 1995;10:S50-3.

26. Parola M, Robino G. Oxidative stress-related molecules and liver fibrosis. J Hepatol 2001;35:297-306.

Source of Support: Nil, Conflict of Interest: None declared.

\section{Author Help: Online submission of the manuscripts}

Articles can be submitted online from http://w ww.journalonweb.com. For online submission, the articles should be prepared in tw o files (first page file and article file). Images should be submitted separately.

1) First Page File:

Prepare the title page, covering letter, acknow ledgement etc. using a word processor program. All information related to your identity should be included here. Use text/rtf/doc/pdf files. Do not zip the files.

2) Article File:

The main text of the article, beginning with the Abstract to References (including tables) should be in this file. Do not include any information (such as acknow ledgement, your names in page headers etc.) in this file. Use text/rtf/doc/pdf files. Do not zip the files. Limit the file size to $400 \mathrm{~kb}$. Do not incorporate images in the file. If file size is large, graphs can be submitted separately as images, without their being incorporated in the article file. This will reduce the size of the file.

3) Images:

Submit good quality color images. Each image should be less than 1024 kb (1 M B) in size. The size of the image can be reduced by decreasing the actual height and width of the images (keep up to about 6 inches and up to about 1200 pixels) or by reducing the quality of image. J PEG is the most suitable file format. The image quality should be good enough to judge the scientific value of the image. For the purpose of printing, always retain a good quality, high resolution image. This high resolution image should be sent to the editorial office at the time of sending a revised article.

4) Legends:

Legends for the figures/images should be included at the end of the article file. 